Nurul Wahdah \& Ade Destri Deviana: Jaudah Tarjamah Mustakhlashat al Buhuts Al Jami'iyyah Min al Lughah al Indunisiyyah Ila al Lughah al 'Arabiyyah Lada Thalabah Qism Ta'lim al Lughah al 'Arabiyyah Fi Jamiah Palangkaraya

\title{
جودة ترجمة مستخلصيات البحوث الجامعية من اللغة الإندونيسية إلى اللغة العربية \\ لدى طلبة قسم تعليم اللغة العربية في جامعة بالنكا ريا الإسلامية الحكومية
}

\section{Nurul Wahdah', Ade Destri Deviana ${ }^{2}$}

IAIN Palangkaraya, Kalimantan Tengah, STIQ Amuntai, Kalimantan Selatan, Email:1nwahdah1980@gmail.com, 2ade.destri.d@gmail.com

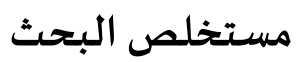

تهدف هذه الدراسة إلى معرفة الأخطاء في ترجمة مستخلصات البحوث الجامعية من

اللغة الإندونيسية إلى اللغة العربية التي قام بها طلبة قسم تعليم اللغة العربية في جامعة بالنكا ريا الإسلامية الحكومياة. المدخل المستخدم هو تحليل الأخطاء بالخطوات التالية: وصف الأخطاء وبيانها وتقويمها. أساليب جمع البيانات بالوثائق وهي مجموعاة مستخلصات البحوث الجامعية لدى طلبة قسم تعليم اللغة العربية في جامعة بالنكاريا الإسلامية الحكومية بعدد 6 عينات. نتييجة الدراسة تدل على أن الأخطاء التي قام بها الطلبة هي الأخطاء في التصنيف اللغوي تشمل الأخطاء النحوية 73،10\% والأخطاء الصرفية 47،2\% والأخطاء الدلالية 7،\%. الأخطاء في تصنيف البنية السطحية تشمل النقصان 7،\%؛، والزيادة 14،87\%، والترتيب الخاطئ 22،13\%، والتشكيل الخاطئ 26،8\%. الأخطاء في تصنيف التحليل المقارن تشمل الأخطاء التطويرية 31،3 \%؛ واللغة الوسطى 78، \%؛، والأخطاء الأخرى 82، \% والأخرى، الأخطاء في تصنيف التأثير التواصلي تشمل الأخطاء الكلية 95، 4\% والأخطاء الجزئية 9191\% وأكثر الأخطاء قام بها الطلبة الأخطاء الدلالية. الكلمات الرئيسية: تحليل الأخطاء، مستخلصهات البحوث الجامعية، تصنيفات الأخطاء 
Nurul Wahdah \& Ade Destri Deviana: Jaudah Tarjamah Mustakhlashat al Buhuts Al Jami'iyyah Min al Lughah al Indunisiyyah lla al Lughah al 'Arabiyyah Lada Thalabah Qism Ta'lim al Lughah al 'Arabiyyah Fi Jamiah Palangkaraya

تعد الترجمة بوصفها سبيلا من سبل التفاهم والتواصل اللغوي1 وهي فن تطبيقى يمثل الحرفة التى لا يمكن إتقانها إلا بالدربة والمران والممارسة استناداً إلى إلى موهب² وإن الترجمة نفسها يمكن أن ينظر إليها على أنها حوار بين النظرية والممارسـة، وبعبارة أخرى أن الترجمة هي نظرية وممارسـة في الحوار لأن العلاقة بين نظرية الترجماة وممارستها الفعلية تمت بالضغط طوال الوقت والتبصر القيم في طبيعة الترجماة وعملها يمكن العثور عليها في النصوص المختلفة التي تقترب بعبور لغة إلى لغة أخرى بطريقة أكثر مكافئ أو مجازياة.

بجانب آخر، ليس الترجمة قواعد بالمعنى المعروف ولكنها مجرد مجموعة من الملاحظات حول الطرق التي حل بها المترجمون المحترفون بعض الصعوبات التي قابلتهم أثناء ترجماتهم للنصوص المختلفة. فالترجمة ليست علما صرفا وليست فنا خالصا ولكنها فن تطبيقي يحتاج إلى المران والتدريب في وجود ملكة أو موهبة طبيعياة. والترجمة من لغة إلى لغة إخرى لها صعوبات الخاصية التي تختلف عن تلك التي نقابلها لو ترجمنا إلى لغة ثالثة. ويرجع إلى اختلاف التركيب دلالة الألفاظ بين اللغات3 ولا شك أيضيا أن امتياز الثقافات وتلاقيها، أدى إلى تأثر الثقافات ببعضهيا البعص.4 وقد تقوم الترجمة بدور سلبي يؤدي إلى تغيير نظام الجملة في اللغة العربية والسبب في ذلك يرجع إلى ضيق المحتوى اللغوي للمترجم وقلة معرفتـ

محمد أحمد منصور، الترجمة بين النظرية والتطبيق: مبادئ ونصوص وقاموس للمصطاحات الإسلامية، القاهرة: دار الكمال للطباعة والنشر، 2006، ص. صند 19

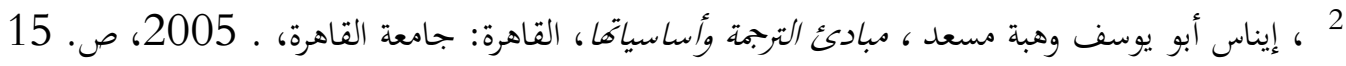

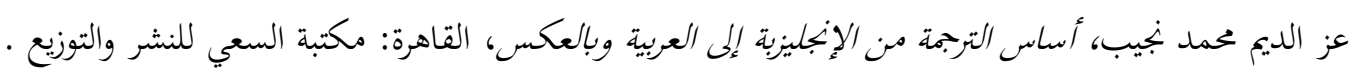

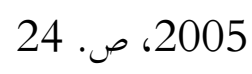

4 حسام الدين مصطفى أمس وقواعد صنعة الترجمة، حملت في ويب www.hosameldin.org، صنس، 2011،

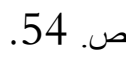


Nurul Wahdah \& Ade Destri Deviana: Jaudah Tarjamah Mustakhlashat al Buhuts Al Jami'iyyah Min al Lughah al Indunisiyyah lla al Lughah al 'Arabiyyah Lada Thalabah Qism Ta'lim al Lughah al 'Arabiyyah Fi Jamiah Palangkaraya

بالتراث الثقافي واللغوي العربي.5 'ويضع تيتلر ثلاثة مبادئ يسميها "قوانين" أو قواعد للترجمة الجيدة وهي: على الترجمة أن تنقل نقلا تاما جميع الأفكار في النص الأصلي، و يجب أن يتفق أسلوب الكتابة وطرائقها مع أسلوب النص الأصلي وطرائقه، ويتب أم تتحلى الترجماة باليسر الذي يتحلى باه النص الأصلي .6 يقسم Simon Chou نماذج الترجماة إلى ثلاثة اتجاهات رئيسية و هي الاتجاه الحوي والاتجاه الثقافي والاتجاه الاستنتاجي.7 لأن في الترجمة عديد من المشكلات التى تواجه علم الترجمة وهي الألفاظ التى تتضمن اشتقاق الألفاظ ومعانيها ودلالاتها واختلاف ذلك من السياق والتراكيب التى تتضمن بناء الجملة وفن مضاهاة التراكيب فى اللغتين. ' وكانت الأخطاء في الترجمة تظهر في لغة الهدف و تنشأ عن جهل بالمبادئ و القواعد الترجمية أو عن سوء تطبيقها. وهي تتجلى عند نقل دلالات الأصب في حفذ ألفاظ أو زيادة كلمات أو عبارات لا وجود لها في الأصل. فلذك لدى المترجم المحترف خمسـة أنواع مختلفة من المعرفة، وهي: مغرفة لغة الهدف، ومعرفة أنماط النصوص، ومعرفة لغة الأصل، ومعرفة بموضوع البحث (معرفة حقيقية))، ومعرفة تقابلية. 9

إن دراسـة الأخطاء هي أيضا جزء أسـاسي من اللغات التطبيقية. وهي توفر

التحقق من نتائج الدراسـات اللغوية التباينية. وتستند مقارنة ثنائية اللغة إلى نظرية

حسام الدين مصطفى، أسس وقواعد صنعة الترجمة، ص. 55

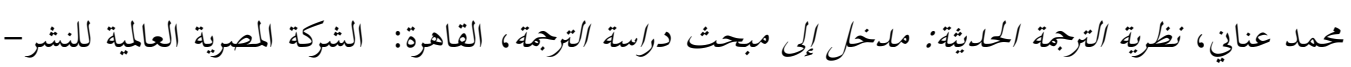
لونجمان، 2003، ص.

7 يوسف نور عوض، علم النص ونظرية الترجمة، مكة المكرمة: دار الثقة للنشر و التوزيع، 1990، 190، ص. 82 8 إيناس أبو يوسف وهبة مسعد، مبادئ الترجمة وأساسياتها، ص. 16

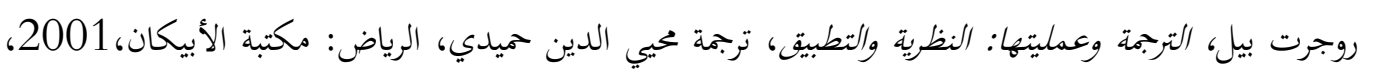
ص. 95 
Nurul Wahdah \& Ade Destri Deviana: Jaudah Tarjamah Mustakhlashat al Buhuts Al Jami'iyyah Min al Lughah al Indunisiyyah lla al Lughah al 'Arabiyyah Lada Thalabah Qism Ta'lim al Lughah al 'Arabiyyah Fi Jamiah Palangkaraya

أن الاختلافات بين اللغة الأم واللغة الثانية التي يجب على المتعلم أن يتعلمهامْ أما التصنيفات الوصفيية للأخطاء هي التصنيف اللغوي، وتصنيف البنية السطحية، وتصنيف التحليل المقارن، وتصنيف التأثير التواصلي. أما التصنيف اللغوي يصنف الأخطاء وفقا للمكون اللغوي المعين لتأثير الخطأ. ويشمل المكون اللغوي الأخطاء الفنولوجية والأخطاء النحوية والأخطاء الصرفياة، والأخطاء الدلالية والمعجم، والخطاب. ويشمل تصنيف البنية السطحية النقصيان (omitting)، والزيادة (adding)، والتشكيل الخاطئ (misforming) والترتيب الخاطئ (misordering). ويستند تصنيف الأخطاء في التصنيف المقارن إلى المقارنة بين تركيب أخطاء اللغة الثانية وأنواع معينة من الإنشاءات. تصنيف التأثير التواصلي يتعامل مع الخطأ من نظر تأثيره على المستمع أو القارئ. ويركز على التمييز بين الأخطاء التي يبدو أنها تسبب سوء الاتصال والأخطاء التي لا تسبب سوء الاتصال.11 أما الأخطاء التطورية تدل على محاولة بناء الافتراضات وهي: (1) المبالغة في التعميم

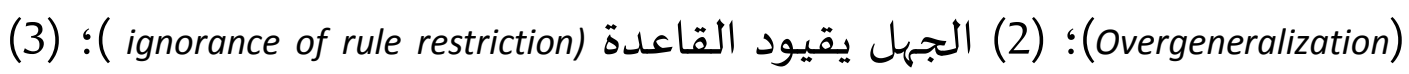
التطبيق الناقص للقواعد ( incomplete appliction of rule)؛ (4) الافتراضات الخاطئة 12 (false concepts hypothesized)

هنا عديد من الدراسـات حول مشكلات الترجمة من اللغة العربية إلى اللغة

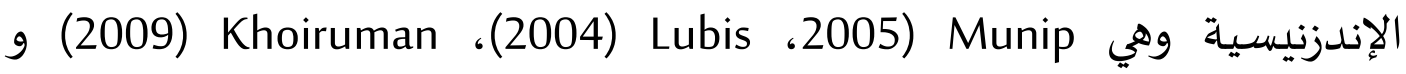
Andriana إلى اللغة العربية عند Tyas (2016) وهي يركز على ترجمة الأسلوب النافي . نتيجة

${ }^{10}$ S. P Corder, Error Analysis and Interlanguage, New York: Oxford University Press, 1981, P. 35

11 Heidi Dulay, Marina Burt, dan Stephen Krashen, Language Two, New York: Oxford University Press, 1982, P. 15-189

12 Jack C. Richards, Error Analysis: A Perspective on Second Language Acquisition, London: Longman Group, 1985, P. 174 
Nurul Wahdah \& Ade Destri Deviana: Jaudah Tarjamah Mustakhlashat al Buhuts Al Jami'iyyah Min al Lughah al Indunisiyyah lla al Lughah al 'Arabiyyah Lada Thalabah Qism Ta'lim al Lughah al 'Arabiyyah Fi Jamiah Palangkaraya

الدراسـات أكثرها تدل على وجود الأخطاء الكثيرة في الترجمة من لغة المصدر إلى اللغة الهدف وأنواعها مختلفة.

أساسا على ذلك، يركز هذا البحث على تحليل الأخطاء في ترجمة

مستخلصات البحوث الجامعية من اللغة الإندونيسية إلى اللغة العربية المستندة إلى افتراضيات الأخطاء التطوريسة في أربعة تصنيفات. أما أسئلة البحث هي: ما أنواع الأخطاء التي تكون في ترجمة مستلخصيات البحوث الجامعية من اللغة الإندونيسية إلى اللغة العربية لدى طلبة قسم تعليم اللغة العربية في جامعة بالنكا ريا الإسلامية الحكومية وما أسبابها وما أكثرها.

\section{منهجية البحث}

المدخل المستخدم في هذا البحث هو مدخل تحليل الأخطاء وهو الإجراءات

لتحليل الأخطاء. الخطوات لتحليل الأخطاء هي وصف الأخطاء وشرحها وتقويمها. 13 أساليب جمع البيانات بالتوثيق وهي مجموعاة مستخلصات البحوث الجامعية لدى طلبة قسم تعليم اللغة العربية في جامعة بالنكا ريا الإسلامية الحكومية بعدد 6

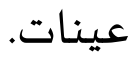
أ. البيانات و المناقشـة فيها

حلّلنا الأخطاء في ترجمة مستخلصات البحوث الجامعية من اللغة الإندونسية إلى اللغة العربية، وتكرار الأخطاء في ترجمة مستخلصات البحوث الجامعياة من الإندونيسية إلى اللغة العربية. 1. الأخطاء في ترجمة مستخلصات البحوث الجامعية من اللغة الإندونسية إلى الى اللغة العربية

${ }^{13}$ Rod Ellis, Second Language Acquisition, Oxford: Oxford University Press, 1986, P. 15-19 
Nurul Wahdah \& Ade Destri Deviana: Jaudah Tarjamah Mustakhlashat al Buhuts Al Jami'iyyah Min al Lughah al Indunisiyyah lla al Lughah al 'Arabiyyah Lada Thalabah Qism Ta'lim al Lughah al 'Arabiyyah Fi Jamiah Palangkaraya

توجد الأخطأ المختلفة في ترجمة مستخلصات البحوث الجامعية من اللغة الإندونسية إلى اللغة العربية تشمل فيما يلي أمثلة الأخطاء و بيانها التي

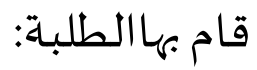

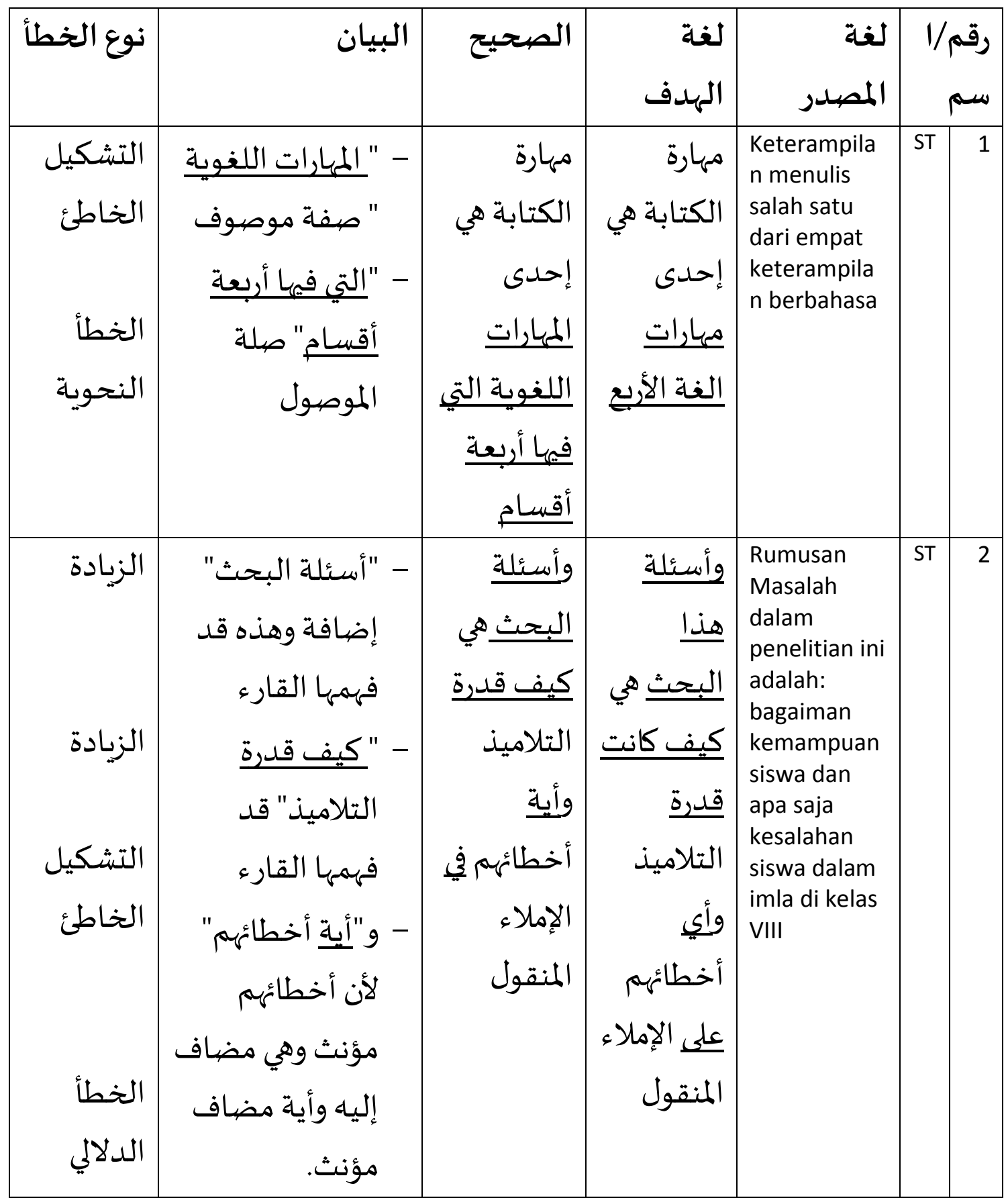


Nurul Wahdah \& Ade Destri Deviana: Jaudah Tarjamah Mustakhlashat al Buhuts Al Jami'iyyah Min al Lughah al Indunisiyyah lla al Lughah al 'Arabiyyah Lada Thalabah Qism Ta'lim al Lughah al 'Arabiyyah Fi Jamiah Palangkaraya

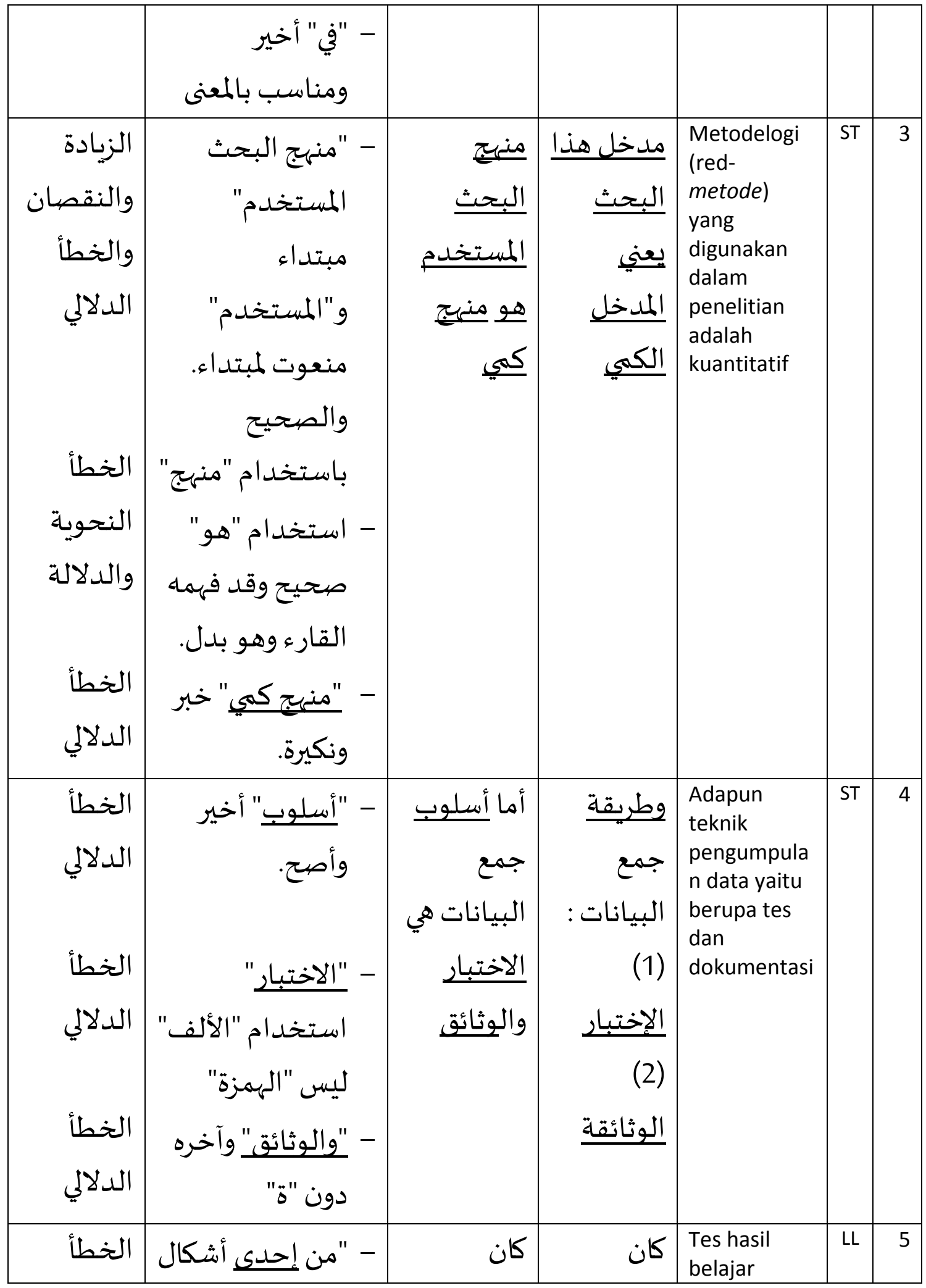


Nurul Wahdah \& Ade Destri Deviana: Jaudah Tarjamah Mustakhlashat al Buhuts Al Jami'iyyah Min al Lughah al Indunisiyyah lla al Lughah al 'Arabiyyah Lada Thalabah Qism Ta'lim al Lughah al 'Arabiyyah Fi Jamiah Palangkaraya

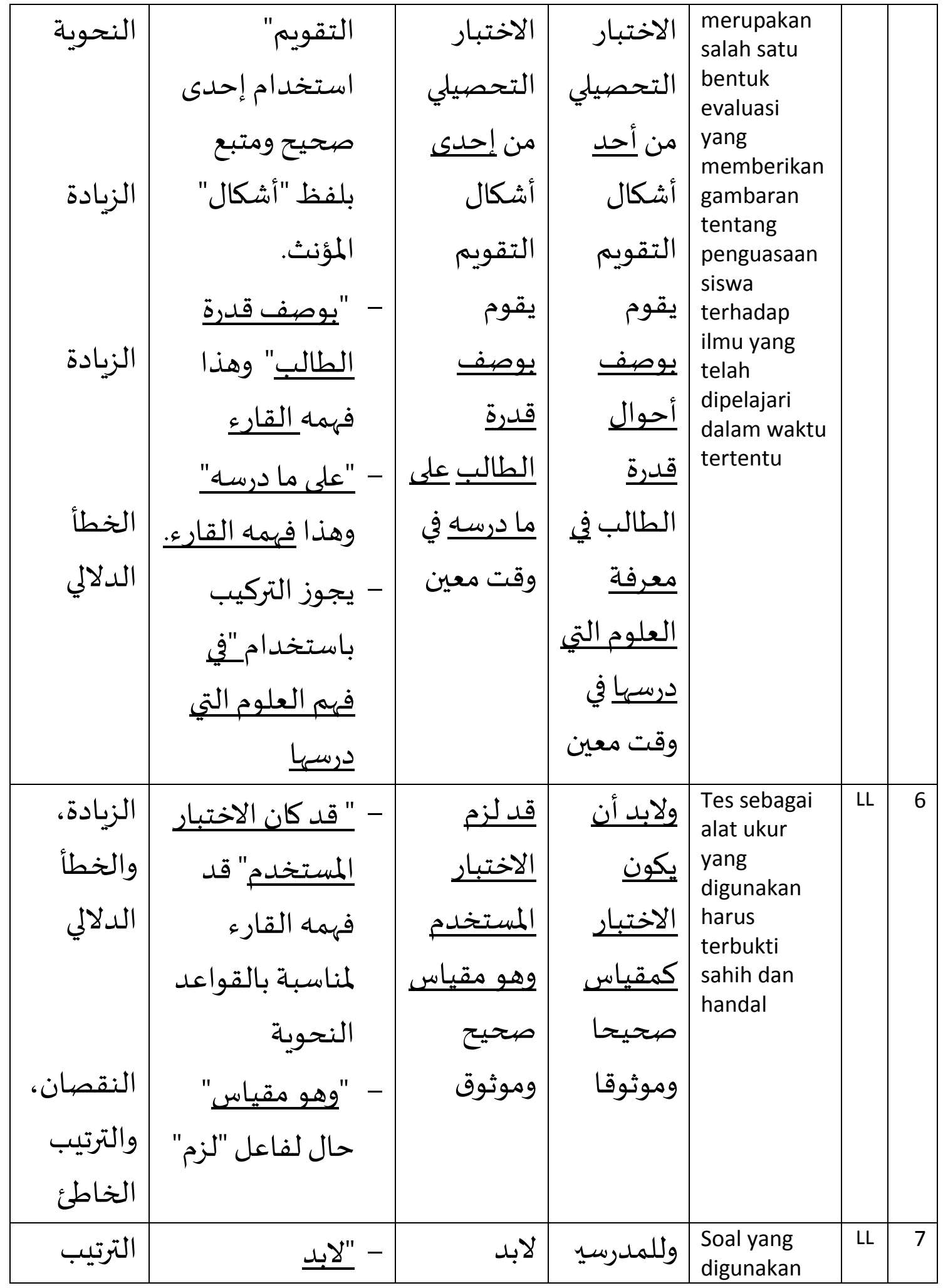


Nurul Wahdah \& Ade Destri Deviana: Jaudah Tarjamah Mustakhlashat al Buhuts Al Jami'iyyah Min al Lughah al Indunisiyyah Ila al Lughah al 'Arabiyyah Lada Thalabah Qism Ta'lim al Lughah al 'Arabiyyah Fi Jamiah Palangkaraya

\begin{tabular}{|c|c|c|c|c|c|c|}
\hline الخاطئ & مقدم في الجملة & 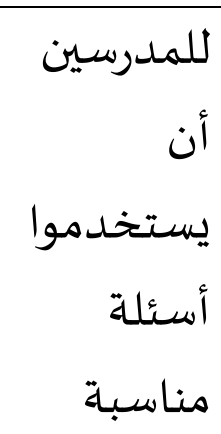 & أن أنسئد لهم & $\begin{array}{l}\text { oleh guru } \\
\text { dalam } \\
\text { pembelajara } \\
\mathrm{n} \text { hendaknya } \\
\text { soal yang } \\
\text { bermutu }\end{array}$ & & \\
\hline الخطأ الدلالي & - أصح باستخددام & المأما هدف المبحث هو & هو هوأما هدف & $\begin{array}{l}\text { Adapun } \\
\text { tujuan dari } \\
\text { penelitian ini } \\
\text { adalah untuk } \\
\text { mengetahui } \\
\text { kualitas } \\
\text { instrument } \\
\text { tes pilihan } \\
\text { ganda pada } \\
\text { lembar kerja }\end{array}$ & $\mathrm{LL}$ & 8 \\
\hline الحطرأ الخطي، & - استخدام نظرية & في الفصل & فى الفصل & $\begin{array}{l}\text { Pada kelas } 4 \\
\text { jumlah } \\
\text { keseluruhan } \\
\text { nya yaitu }\end{array}$ & LL & 9 \\
\hline التشكيل & 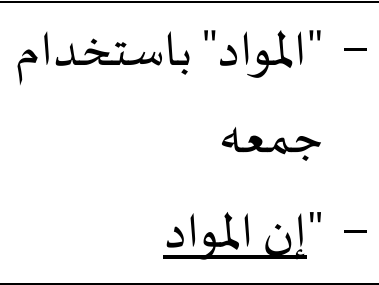 & التعلم المواد & التعلت المادة & $\begin{array}{l}\text { Materi } \\
\text { belajar } \\
\text { merupakan } \\
\text { salah satu } \\
\text { komponen } \\
\text { pembelajara }\end{array}$ & SY & 10 \\
\hline
\end{tabular}


Nurul Wahdah \& Ade Destri Deviana: Jaudah Tarjamah Mustakhlashat al Buhuts Al Jami'iyyah Min al Lughah al Indunisiyyah Ila al Lughah al 'Arabiyyah Lada Thalabah Qism Ta'lim al Lughah al ‘Arabiyyah Fi Jamiah Palangkaraya

\begin{tabular}{|c|c|c|c|c|c|c|}
\hline والخاطئ & 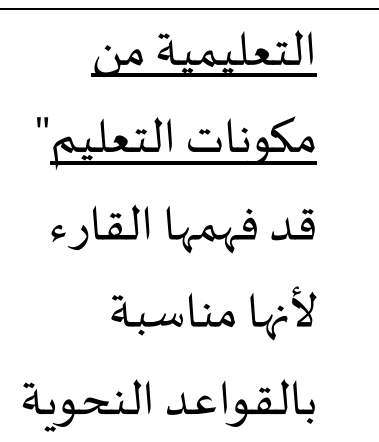 & التعليم & مكزء & $\mathrm{n}$ & & \\
\hline 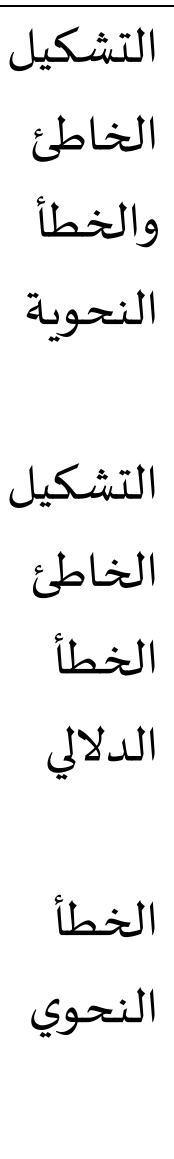 & 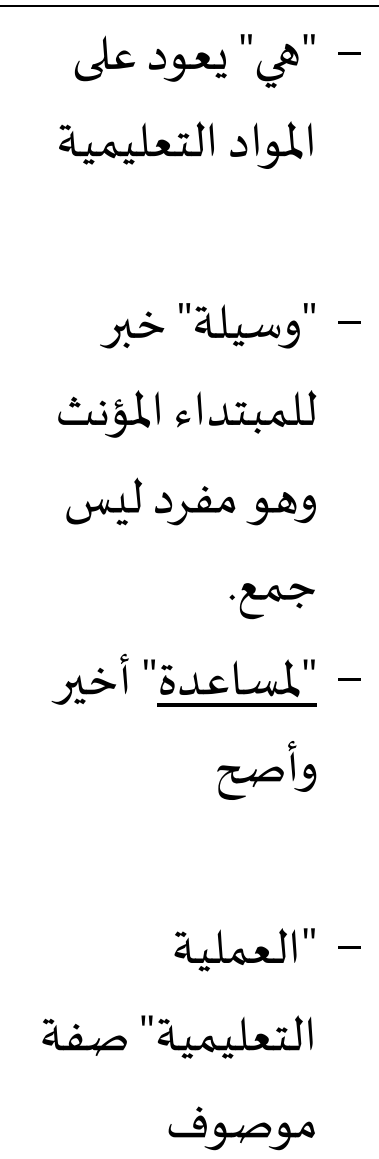 & وهي وسيلة & وهول ولنصئل & $\begin{array}{l}\text { Yang } \\
\text { berfungsi } \\
\text { sebagai } \\
\text { sarana untuk } \\
\text { membantu } \\
\text { proses } \\
\text { belajar } \\
\text { mengajar }\end{array}$ & SY & 11 \\
\hline والزيادة & - بطوير الجملة & منهجية الستخدمت & 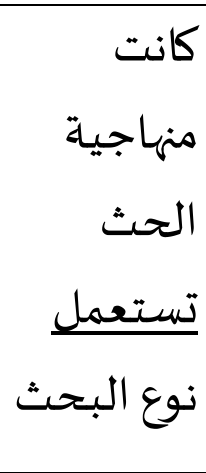 & $\begin{array}{l}\text { Metode } \\
\text { penelitian ini } \\
\text { menggunaka } \\
\mathrm{n} \text { jenis } \\
\text { penelitian } \\
\text { deskriptif } \\
\text { dengan } \\
\text { pendekatan } \\
\text { kualitatif } \\
\text { melalui }\end{array}$ & SY & 12 \\
\hline
\end{tabular}


Nurul Wahdah \& Ade Destri Deviana: Jaudah Tarjamah Mustakhlashat al Buhuts Al Jami'iyyah Min al Lughah al Indunisiyyah lla al Lughah al 'Arabiyyah Lada Thalabah Qism Ta'lim al Lughah al 'Arabiyyah Fi Jamiah Palangkaraya

\begin{tabular}{|c|c|c|c|c|c|c|}
\hline الخطرأ & " و "استخدمتت" & والكيفي & الومل الكيفي & teknik isi & & \\
\hline الزيادة & أحستخدام "نتائج" & أما نتائج & أمذا ألحاصل في & $\begin{array}{l}\text { Hasil dari } \\
\text { penelitian ini } \\
\text { adalah }\end{array}$ & SY & 13 \\
\hline الخطأ الدلالي الدطأ & 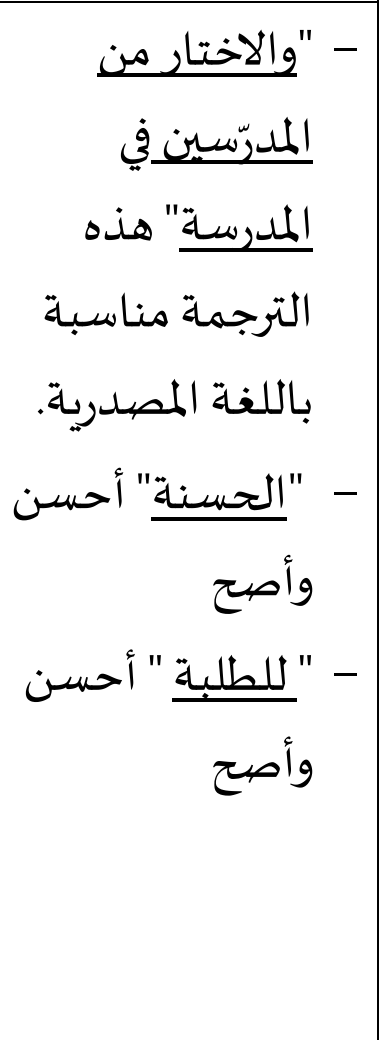 & 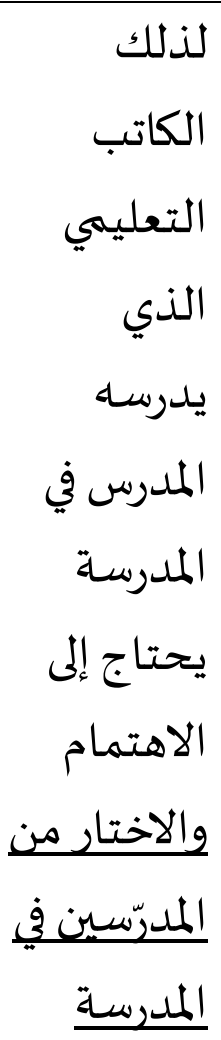 & 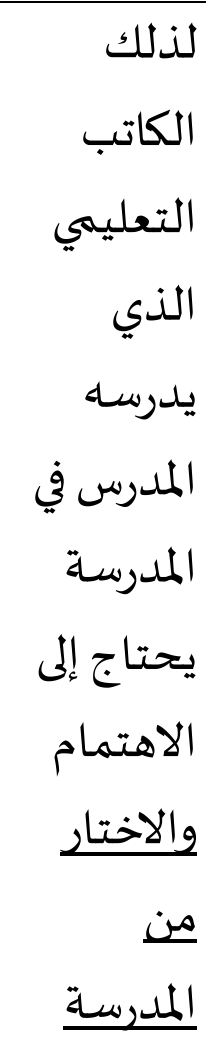 & $\begin{array}{l}\text { Maka atas } \\
\text { dasar itu, } \\
\text { buku ajar } \\
\text { yang } \\
\text { diajarkan di } \\
\text { sekolah } \\
\text { perlu } \\
\text { mendapat } \\
\text { perhatian } \\
\text { dan } \\
\text { penyeleksian } \\
\text { dari guru } \\
\text { guru di } \\
\text { sekolah } \\
\text { sehingga } \\
\text { buku ajar } \\
\text { tesebut } \\
\text { dapat } \\
\text { memberikan } \\
\text { nilai yang } \\
\text { baik bagi } \\
\text { peserta didik }\end{array}$ & & 14 \\
\hline
\end{tabular}


Nurul Wahdah \& Ade Destri Deviana: Jaudah Tarjamah Mustakhlashat al Buhuts Al Jami'iyyah Min al Lughah al Indunisiyyah lla al Lughah al 'Arabiyyah Lada Thalabah Qism Ta'lim al Lughah al 'Arabiyyah Fi Jamiah Palangkaraya

\begin{tabular}{|c|c|c|c|c|c|c|}
\hline & & 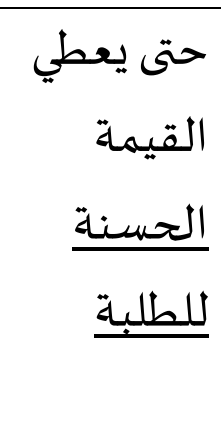 & لعتى وهو & & & \\
\hline الخطأ & "هو "هو بلأنه في الجملة & هذا هـا سؤال & أما سؤال & $\begin{array}{l}\text { Penelitian ini } \\
\text { berdasarkan } \\
\text { pada } \\
\text { rumusan } \\
\text { masalah } \\
\text { yaitu }\end{array}$ & AS & 16 \\
\hline النقصيان & 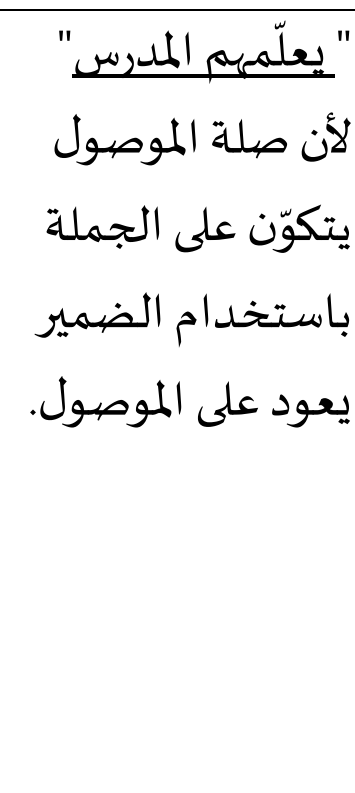 & 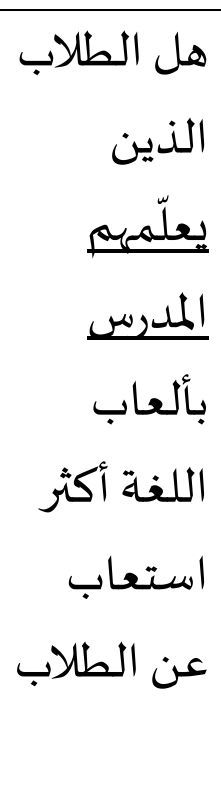 & 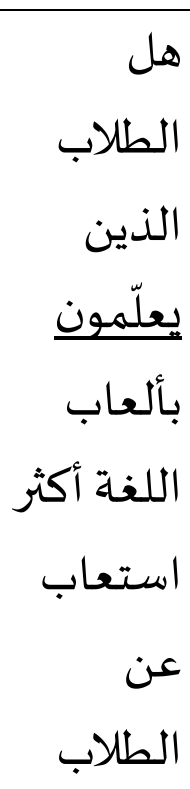 & $\begin{array}{l}\text { Apakah } \\
\text { siswa yang } \\
\text { diajarkan } \\
\text { melalui } \\
\text { permainan } \\
\text { bahasa lebih } \\
\text { efektif } \\
\text { penguasaan } \\
\text { kosakatanya }\end{array}$ & AS & 17 \\
\hline التقصيان & 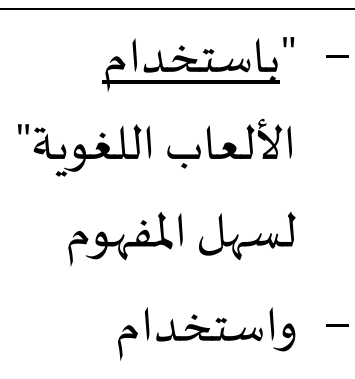 & هل الألعاب & الذلّ & $\begin{array}{l}\text { Apakah } \\
\text { siswa yang } \\
\text { diajarkan } \\
\text { melalui } \\
\text { permainan } \\
\text { bahasa lebih } \\
\text { efektif } \\
\text { penguasaan }\end{array}$ & AS & 18 \\
\hline
\end{tabular}


Nurul Wahdah \& Ade Destri Deviana: Jaudah Tarjamah Mustakhlashat al Buhuts Al Jami'iyyah Min al Lughah al Indunisiyyah lla al Lughah al 'Arabiyyah Lada Thalabah Qism Ta'lim al Lughah al 'Arabiyyah Fi Jamiah Palangkaraya

\begin{tabular}{|c|c|c|c|c|c|c|}
\hline الخاطئ & "الألعاب اللغوية" & الاستعاب & اللألعاب الستبة أكثر & $\begin{array}{l}\text { kosakatanya } \\
\text { ? }\end{array}$ & & \\
\hline الزيادة الترتيب & 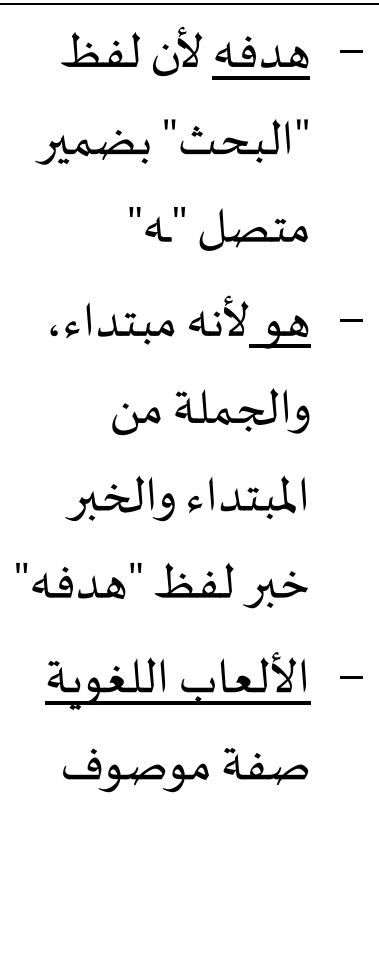 & لقعاس الألعابـ هو & لوهد & $\begin{array}{l}\text { Tujuan } \\
\text { penelitian ini } \\
\text { adalah untuk } \\
\text { mengukur } \\
\text { efektifitas } \\
\text { permainan } \\
\text { bahasa }\end{array}$ & AS & 19 \\
\hline الزيادة & "هي" لأناه خبر & أما فرضية & أما فرضية & $\begin{array}{l}\text { Hipotesa } \\
\text { penelitian } \\
\text { yang } \\
\text { diajukan } \\
\text { yaitu }\end{array}$ & AS & 20 \\
\hline الخطأ & للفناسبة بالقواعد & أما مكان المبحث هو & البــى هذا & $\begin{array}{l}\text { Adapun } \\
\text { tempat } \\
\text { penelitian ini } \\
\text { dilaksanakan } \\
\text { di MIN }\end{array}$ & AS & 21 \\
\hline
\end{tabular}


Nurul Wahdah \& Ade Destri Deviana: Jaudah Tarjamah Mustakhlashat al Buhuts Al Jami'iyyah Min al Lughah al Indunisiyyah lla al Lughah al 'Arabiyyah Lada Thalabah Qism Ta'lim al Lughah al 'Arabiyyah Fi Jamiah Palangkaraya

\begin{tabular}{|c|c|c|c|c|c|c|}
\hline الختاطئي التيب & 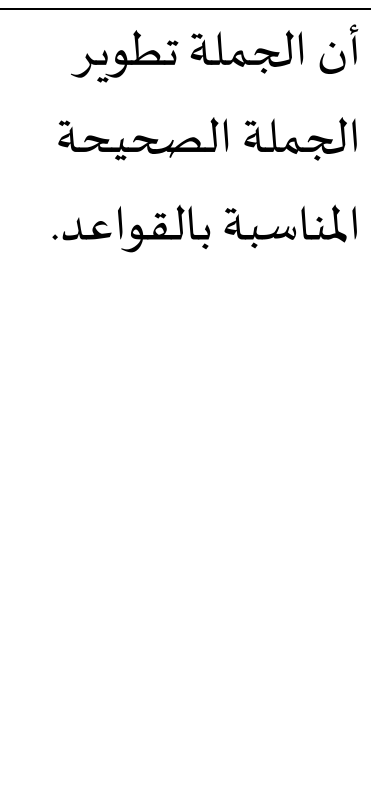 & 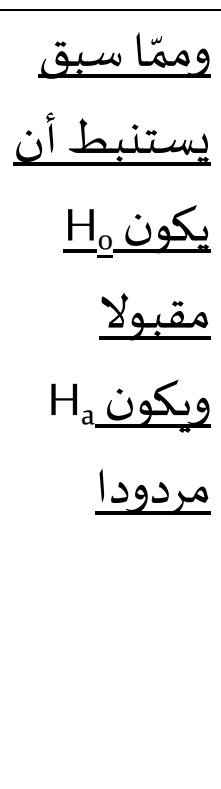 & 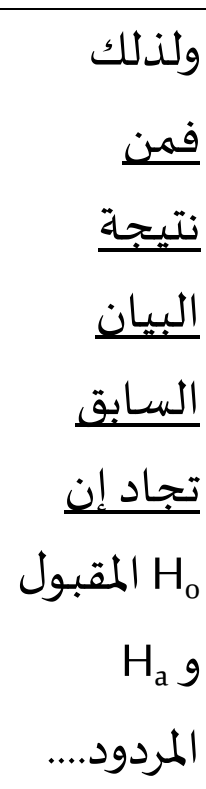 & $\begin{array}{l}\text { Dengan hasil } \\
\text { keterangan } \\
\text { tersebut } \\
\text { dapat } \\
\text { disimpulkan } \\
\text { bahwa } \mathrm{H}_{\mathrm{a}} \\
\text { diterima } \mathrm{H}_{0} \\
\text { ditolak }\end{array}$ & AS & 22 \\
\hline الخطأ الدلالي & "الدروس الأخرى" & الدل تكون في & الد بل تكون في & $\begin{array}{l}\text { Tetapi juga } \\
\text { pengajaran } \\
\text { mata } \\
\text { pelajaran } \\
\text { lainnya }\end{array}$ & $A D$ & 23 \\
\hline 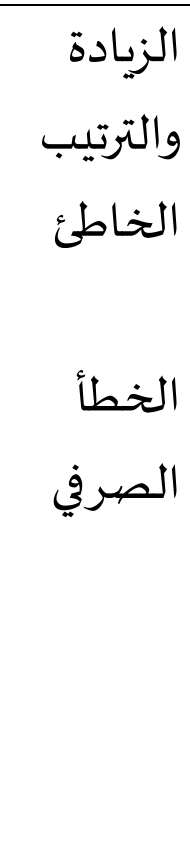 & - مناسبة - مبالقواعد الجملة & هذي الإضيافة & 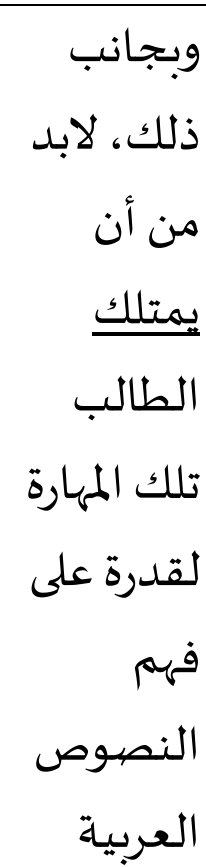 & $\begin{array}{l}\text { Selain itu } \\
\text { kemampuan } \\
\text { memahami } \\
\text { ini harus } \\
\text { dimiliki siswa } \\
\text { untuk dapat } \\
\text { memahami } \\
\text { teks dan } \\
\text { menjawab } \\
\text { pertanyaan }\end{array}$ & $A D$ & 24 \\
\hline
\end{tabular}


Nurul Wahdah \& Ade Destri Deviana: Jaudah Tarjamah Mustakhlashat al Buhuts Al Jami'iyyah Min al Lughah al Indunisiyyah Ila al Lughah al 'Arabiyyah Lada Thalabah Qism Ta'lim al Lughah al 'Arabiyyah Fi Jamiah Palangkaraya

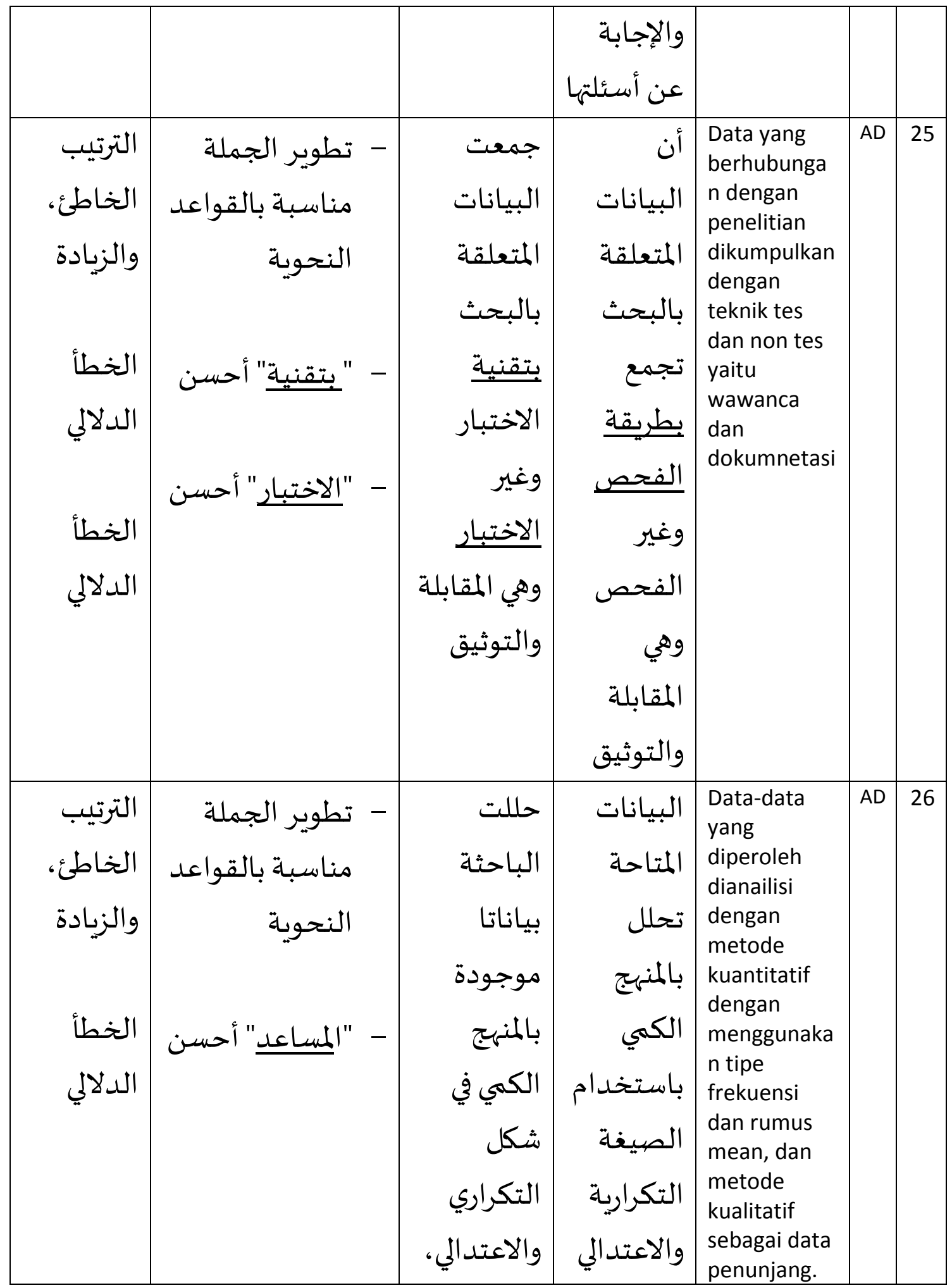


Nurul Wahdah \& Ade Destri Deviana: Jaudah Tarjamah Mustakhlashat al Buhuts Al Jami'iyyah Min al Lughah al Indunisiyyah lla al Lughah al 'Arabiyyah Lada Thalabah Qism Ta'lim al Lughah al ‘Arabiyyah Fi Jamiah Palangkaraya

\begin{tabular}{|c|c|c|c|c|c|c|}
\hline & & لمم المنهرج. & الكالبيفيانات الزئهيج & & & \\
\hline التختبـ الزئ & - مناسبـة بالقواعد الجملة & 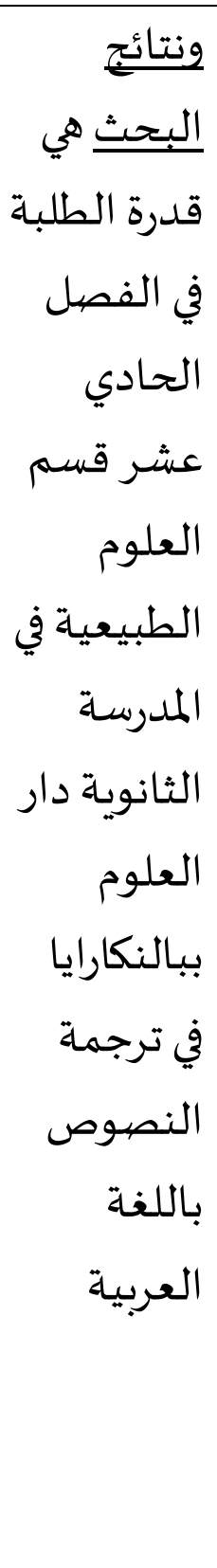 & 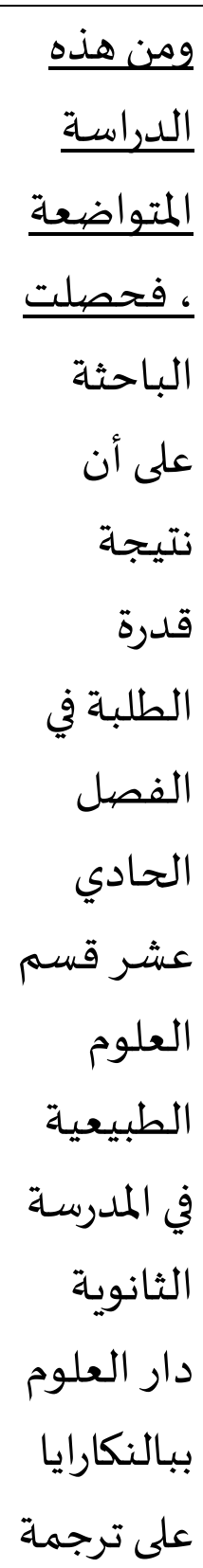 & $\begin{array}{l}\text { Hasil } \\
\text { penelitian, } \\
\text { kemampuan } \\
\text { siswa kelas } \\
\text { XI-IPA MA } \\
\text { Darul Ulum } \\
\text { Palangka } \\
\text { Raya dalam } \\
\text { memahami } \\
\text { isi teks } \\
\text { bacaan } \\
\text { berbahasa } \\
\text { Arab dari } \\
\text { segi } \\
\text { menerjemah } \\
\text { kan teks }\end{array}$ & $A D$ & 27 \\
\hline
\end{tabular}


Nurul Wahdah \& Ade Destri Deviana: Jaudah Tarjamah Mustakhlashat al Buhuts Al Jami'iyyah Min al Lughah al Indunisiyyah Ila al Lughah al 'Arabiyyah Lada Thalabah Qism Ta'lim al Lughah al ‘Arabiyyah Fi Jamiah Palangkaraya

\begin{tabular}{|c|c|c|c|c|c|c|}
\hline & & & النصوصية & & & \\
\hline 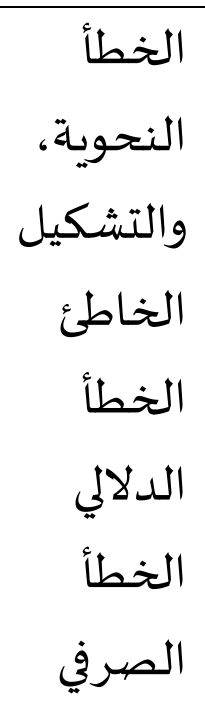 & 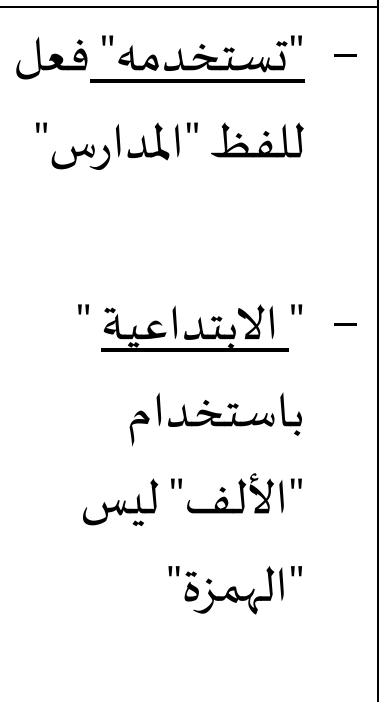 & 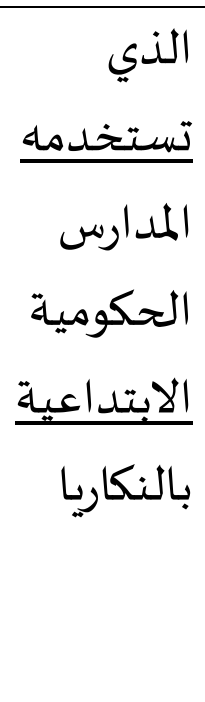 & الذيا & $\begin{array}{l}\text { Yang } \\
\text { digunakan } \\
\text { sekolah } \\
\text { sekolah } \\
\text { madrasah } \\
\text { ibtidaiyyah } \\
\text { di } \\
\text { palangkaray } \\
\text { a }\end{array}$ & $\mathrm{MA}$ & 28 \\
\hline 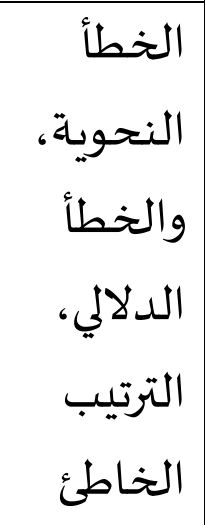 & 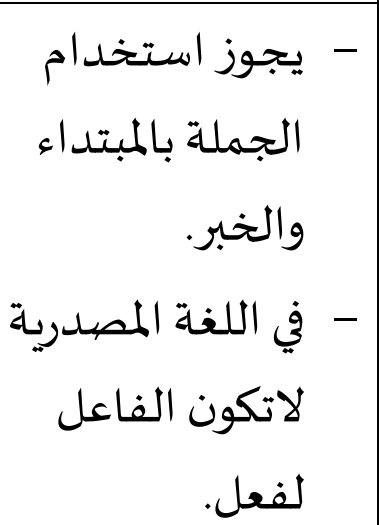 & إعداد العتاب الدراسي & إلبنغي على العداد & $\begin{array}{l}\text { Penyusunan } \\
\text { buku yang } \\
\text { dilakukan } \\
\text { dengan } \\
\text { cermat dan } \\
\text { tepat sangat } \\
\text { penting } \\
\text { untuk } \\
\text { dilakukan }\end{array}$ & MA & \\
\hline والزيادة & 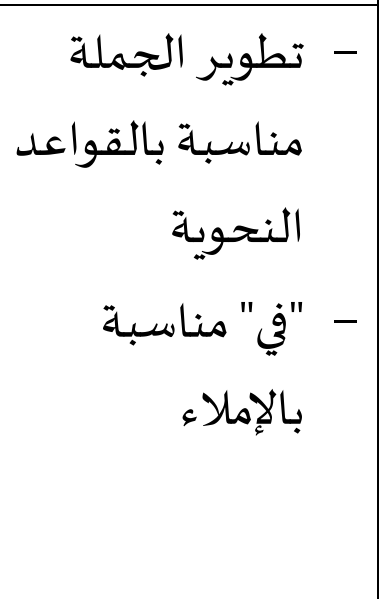 & واستخدم الباحث & 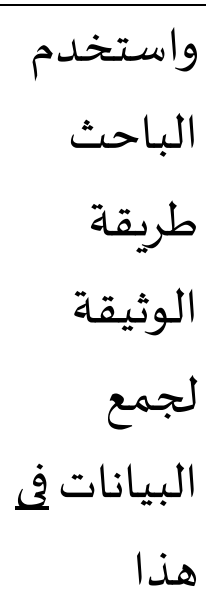 & $\begin{array}{l}\text { Dalam } \\
\text { pengumpula } \\
\mathrm{n} \text { data } \\
\text { peneliti } \\
\text { menggunaka } \\
\mathrm{n} \\
\text { dokumentasi }\end{array}$ & MA & 29 \\
\hline
\end{tabular}


Nurul Wahdah \& Ade Destri Deviana: Jaudah Tarjamah Mustakhlashat al Buhuts Al Jami'iyyah Min al Lughah al Indunisiyyah lla al Lughah al 'Arabiyyah Lada Thalabah Qism Ta'lim al Lughah al 'Arabiyyah Fi Jamiah Palangkaraya

\begin{tabular}{|c|c|c|c|c|c|c|}
\hline & & & البحث & & & \\
\hline 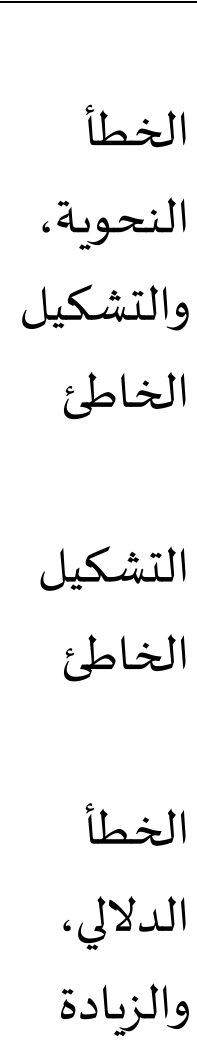 & 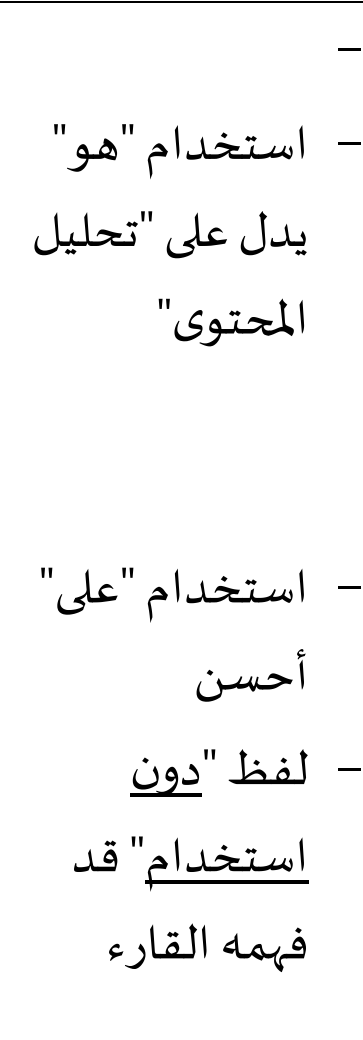 & 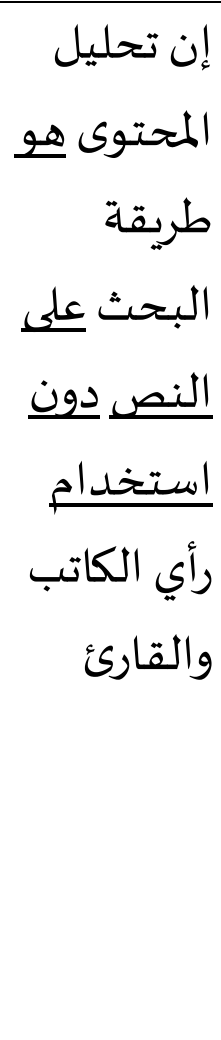 & 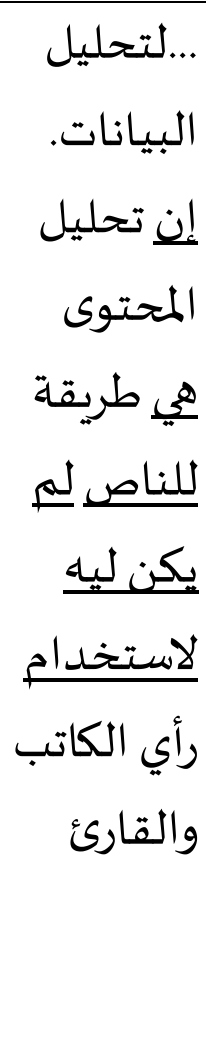 & $\begin{array}{l}\text { Analisis isi } \\
\text { merupakan } \\
\text { sebuah } \\
\text { metode } \\
\text { penelitian } \\
\text { terhadap } \\
\text { sebuah teks } \\
\text { tanpa harus } \\
\text { meminta } \\
\text { pendapat } \\
\text { penulis buku } \\
\text { maupun } \\
\text { pembaca } \\
\text { buku }\end{array}$ & MA & 30 \\
\hline التراطئ الخئ & 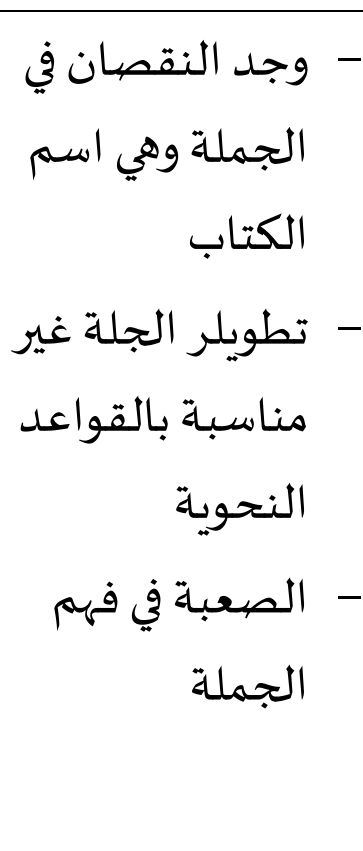 & 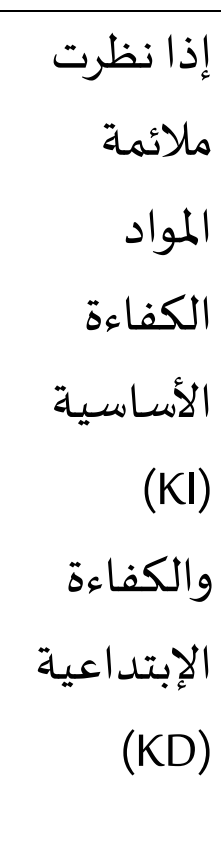 & محتدوى الكتوي & $\begin{array}{r}\text { Kelayakan isi } \\
\text { dalam buku } \\
\text { "Aku cinta } \\
\text { Bahasa Arab } \\
\text { Madrasah } \\
\text { Ibtidaiyyah } \\
\text { kelas V" } \\
\text { Penerbit Tiga } \\
\text { Serangkai } \\
\text { sangat layak } \\
\text { digunakan } \\
\text { jika dilihat } \\
\text { dari } \\
\text { kesesuiaian } \\
\text { uraian } \\
\text { materi } \\
\text { kompetensi } \\
\text { Isi (KI) dan }\end{array}$ & MA & 31 \\
\hline
\end{tabular}


Nurul Wahdah \& Ade Destri Deviana: Jaudah Tarjamah Mustakhlashat al Buhuts Al Jami'iyyah Min al Lughah al Indunisiyyah lla al Lughah al 'Arabiyyah Lada Thalabah Qism Ta'lim al Lughah al 'Arabiyyah Fi Jamiah Palangkaraya

\begin{tabular}{|c|c|c|c|}
\hline الدلالي & 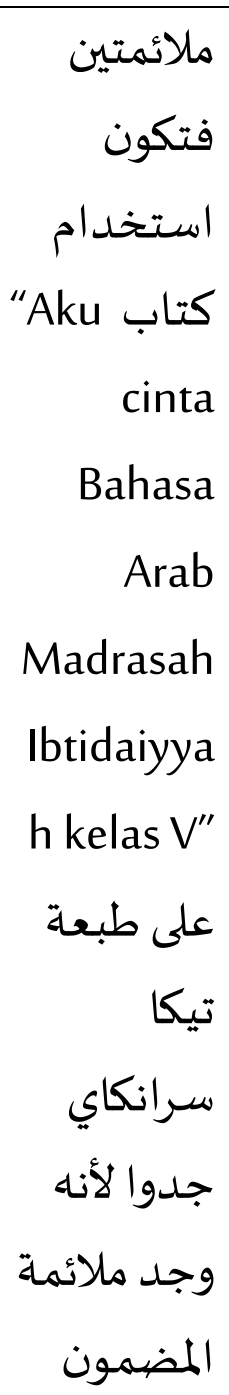 & 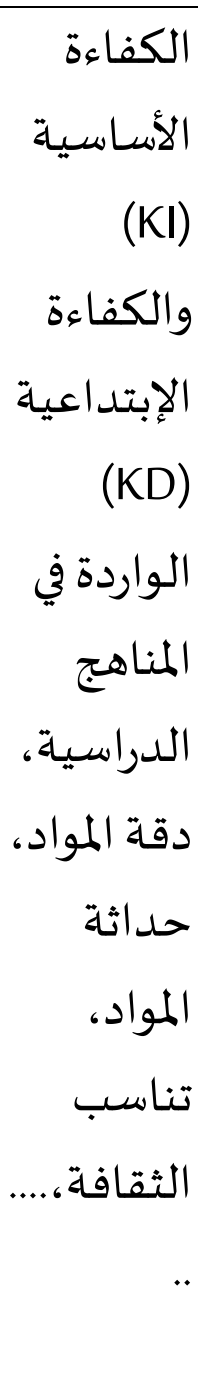 & $\begin{array}{r}\text { Kompetensi } \\
\text { dasar (KD) }\end{array}$ \\
\hline
\end{tabular}

الأسباب العامة في الأخطاء التي قام بها الطلبة في الأمثلة السابقة هي: (أ)

المبالغة في التعميم (Overgeneralization)؛ وهي تتضمن مثلا استعمال قانون قاعدي، فمن الجائز مثلا أن يستعمل الطالب صيغة الفعل المضارع دون مورفيم المفرد الغائب مع جميع الضمائر. المبالغة تشمل الحالات التى يأتي فيها المتعلم ببنية خاطئة على أساس تجربته أساس مع أبنية أخرى في اللغة 
Nurul Wahdah \& Ade Destri Deviana: Jaudah Tarjamah Mustakhlashat al Buhuts Al Jami'iyyah Min al Lughah al Indunisiyyah Ila al Lughah al 'Arabiyyah Lada Thalabah Qism Ta'lim al Lughah al 'Arabiyyah Fi Jamiah Palangkaraya

المدروسة؛؛14 (ب) الجهل بقيود القاعدة (Ignorance of Rule Restriction). وهي ترتبط بتعميم الأبنية الخاطئة عدم مراعاة قيود الأبنية، أي تطبيق بعض القاعدة في

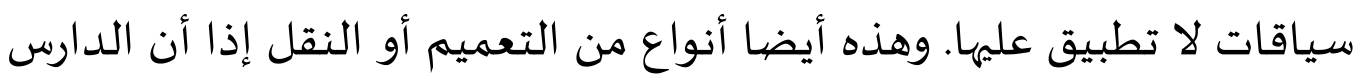
يستخدم قاعدة سبق له اكتسبها وهو يبقها هنا في مواقف جديد و يمكننا أن نفسر بعض أخطاء قيود القاعدة في ضوء القياس، و هناك حالات أخرى قد تكون ناتجة عن استظهار القواعد عن ظهر قلب دون فهم لها؛ 15(ج) والتطبيق الناقص للقواعد (Incomplete Appliction of Rule). هناك نوع من الأخطاء التي تسهى بالأخطاء التطورية وتنتج هذه الأخطاء عن افتراض خاطئ و فهم خاطئ False Concepts ( لأسس التمييز في اللغة الأجنبية؛ (د) الافتراضات الخاطئة Hypothesized). بالإضافة للمدى الواسع للأخطاء داخل ذات العلاقة بالتعلم الخاطئ للقواعد على مستويات مختلفة فهناك نوع من الأخطاء التطويرية ناتج عن فهم خاطئ لأسس التميز في لغذة الهدف. بجانب ذلك يعرف أن الطلبة يستخدمون المفردات غير الشـائعة ولذلك هم وقعوا الأخطاء الدلالية الكثيرة. كذلك في تطبيق النحو، هم مازالوا وجدوا مشكلات في استخدام القواعد الصحيحة. وطبعا هذه الأخطاء تكون شيئا مهما للمعالجـة.

\section{2. تكرار الأخطاء في ترجمة مستخلصيات البحوث الجامعية من الإندونيسية إلى اللغة العربية}

فيما يلي تكرار الأخطاء التي قام بها الطلبة في ترجماة مستخلصات بحوثهم

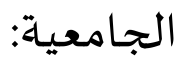

14

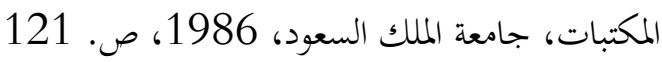
15 محمود إسماعيل صيني وإسحاق محمد الأمين، التقابل اللغوي وتحليل الأخطاء، ص. لمبل 123 
Nurul Wahdah \& Ade Destri Deviana: Jaudah Tarjamah Mustakhlashat al Buhuts Al Jami'iyyah Min al Lughah al Indunisiyyah Ila al Lughah al 'Arabiyyah Lada Thalabah Qism Ta'lim al Lughah al 'Arabiyyah Fi Jamiah Palangkaraya

\begin{tabular}{|c|c|c|c|c|c|c|c|c|c|c|c|c|c|}
\hline \multirow{2}{*}{ 可. } & \multicolumn{2}{|c|}{ تصنيف التأثير } & \multicolumn{3}{|c|}{ تصنيف التحليل } & \multicolumn{4}{|c|}{ تصنيف البنية } & \multicolumn{3}{|c|}{ التصنيف اللغوي } & \multirow[t]{2}{*}{ اسم } \\
\hline & ד. & 离 & $\begin{array}{l}\bar{x} \\
y \\
y \\
\bar{y} \\
\bar{y} \\
y \\
y\end{array}$ & $\begin{array}{l}\overline{3} \\
\overline{3} \\
3 \\
3\end{array}$ & $\begin{array}{l}\bar{x} \\
y \\
y \\
u\end{array}$ & 哥 & 裏: & .3.3. & 可 & 辛 & $\overline{\bar{g}}$ & $\overline{3}$ & \\
\hline 20 & 1 & 1 & 0 & 3 & 0 & 0 & 2 & 3 & 1 & 7 & 0 & 2 & س ت \\
\hline 24 & 7 & 2 & 0 & 0 & 0 & 1 & 3 & 3 & 2 & 5 & 0 & 1 & ل ل \\
\hline 23 & 3 & 0 & 0 & 2 & 2 & 3 & 1 & 3 & 1 & 4 & 1 & 3 & س ي \\
\hline 16 & 0 & 3 & 1 & 0 & 0 & 2 & 3 & 3 & 2 & 0 & 0 & 2 & أ س \\
\hline 14 & 0 & 0 & 0 & 0 & 1 & 0 & 4 & 4 & 0 & 4 & 1 & 0 & أد \\
\hline 24 & 1 & 0 & 0 & 2 & 1 & 4 & 3 & 2 & 1 & 4 & 1 & 5 & م أ \\
\hline 121 & 12 & 6 & 1 & 7 & 4 & 10 & 16 & 18 & 7 & 24 & 3 & 13 & 牙. \\
\hline & $\begin{array}{l}9 ، 9 \\
\% 1\end{array}$ & $\begin{array}{l}4 ، 9 \\
\% 5\end{array}$ & $\begin{array}{r}0.8 \\
2\end{array}$ & $\begin{array}{r}5.78 \\
\%\end{array}$ & $\begin{array}{r}3631 \\
\%\end{array}$ & $\begin{array}{l}8.2 \\
\% 6\end{array}$ & $\begin{array}{r}136 \\
22 \\
\%\end{array}$ & $\begin{array}{r}14 ، \\
87 \\
\%\end{array}$ & $\begin{array}{r}5.7 \\
\%\end{array}$ & $\begin{array}{r}19 ، \\
83 \\
\%\end{array}$ & $\begin{array}{l}2.4 \\
\% 7\end{array}$ & $\begin{array}{r}10 \\
74 \\
\%\end{array}$ & 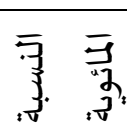 \\
\hline & 5 & 9 & 12 & 8 & 10 & 6 & 3 & 2 & 7 & 1 & 11 & 4 & 氛。 \\
\hline
\end{tabular}

أساسا على الجذول السابق يعرف أن الأخطاء التي يقفها الطلبة في

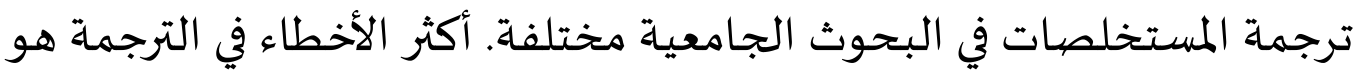

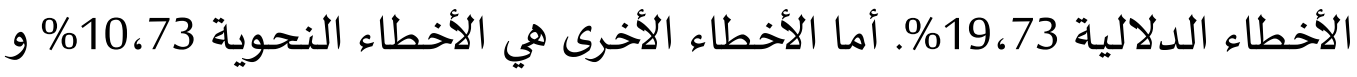

الأخطاء الصرفية 47،2\%، النقصان 7،5\%، و الزيادة 87، 14\%، و الترتيب

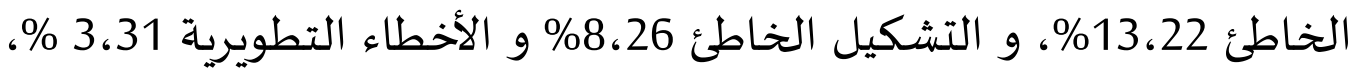


Nurul Wahdah \& Ade Destri Deviana: Jaudah Tarjamah Mustakhlashat al Buhuts Al Jami'iyyah Min al Lughah al Indunisiyyah lla al Lughah al 'Arabiyyah Lada Thalabah Qism Ta'lim al Lughah al 'Arabiyyah Fi Jamiah Palangkaraya

واللغة الوسطى 78،\%٪، والأخطاء الأخرى 82، \% والأخطاء الكلية 95،95\%

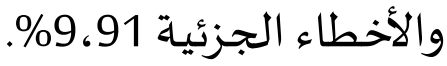

أخطاء الترجمة التي قام بها الطلبة تنتشر في جميع تصنيفات معتدلة.

والأخطاء الدلالية التي قام بها الطلبة كثيرا بسبب قليل معرفتهم في المفردات الشائع الاستخدام في مجال الكتابة الأكاديمية والبحوث العلمية. ومازالت المفردات المستخدمة مختلطة بذوق لغة المصدر.

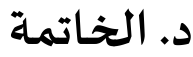

توجد الأخطاء الكثيرة التي قام بها الطلبة في ترجمة مستخلصات البحوث

الجامعياة من اللغة الإندونيسية واللغة العربية. وقعت الأخطاء في أربع تصنيفات وهي في التصنيف اللغوي وتصنيف البنية السطحية وتصنيف التحليل المقارن وتصنيف التأثير التواصلي. أما الأخطاء التي توجد في الترجمة هي الأخطاء الدلالية 73،19\%. والأخطاء النحوية 73، 10\% والأخطاء الصرفية 47،2\%، والنقصان 7،5\%، والزيادة 87،14\%، والترتيب الخاطئ 22، 13\%، والتشكيل الخاطئ 26، \% \% والأخطاء التطويرية 31،3 \%، واللغة الوسطى 78، 5\%، والأخطاء الأخرى 82،0\% والأخطاء الكلية 95،\% والأخطاء الجزئية 91،9\%. والأخطاء الأكثر هي الأخطاء

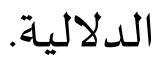

ويلزم على مدرس اللغة العربية اهتمام الأخطاء التي قام بها الطلبة كثيرا بتطوير مادة الترجمة من اللغة الإندونيسية إلى اللغة العربية المستندة إلى أخطائهم. ويلزم على الطلبة ترقية استيعاب المفردات الشائع الاستخدام وأنماط الجملة في اللغة العربية والتعبيرات العامة. 
Nurul Wahdah \& Ade Destri Deviana: Jaudah Tarjamah Mustakhlashat al Buhuts Al Jami'iyyah Min al Lughah al Indunisiyyah Ila al Lughah al 'Arabiyyah Lada Thalabah Qism Ta'lim al Lughah al 'Arabiyyah Fi Jamiah Palangkaraya

\section{المراجع}

أبو يوسف، إيناس و مسعد، هبة. مبادئ الترجمة وأساسياتها. القاهرة: جامعة القاهرة.

الحطيب، طاهر يوسف. المعجم المفصل في الإعراب. سنقافورة: الحرمين. 1991. اليسوعي، لويس معلوف. المنجد في اللغة والأعلام طبيعة جديدة منقحة. بيروت: دار المشرق. 2003

بيل، روجرت. الترجمة وعمليتها: النظرية والتطبيق. ترجماة محيي الدين حميدي. الرياض: مكتبـة الأبيكان. 2001.

صيني، محمود إسماعيل وإسحاق محمد الأمين. التقابل اللغوي وتحليل الأخطاء. الرياض: عمادة شؤون المكتبات، جامعة الملك السعود. . 1986

عوض، يوسف نور. عله النص ونظرية التوجمة. مكة المكرمة: دار الثقة للنشر و التوزع.

عناني، محمد. نظرية التوجمة الحسيثة: ملدخل إلى مبحث دراسة التوجمة. القاهرة: الشركة المصرية العالمية للنشر-لونجمان. 2003.

مصطفى، إبراهيم والآخرون. 1998. المعجم الوسيط. استانبول: دار الدعوة مصطفى، حسام الدين. أبسس وقواعل صنعة التوجمة. .2011

منصور، محمد أحمد. 2006. الترجمة بين النظرية والتطبيق: مبادئ ونصيوص وقاموس للمصطلحات الإسلامية. القاهرة: دار الكمال للطباعة و النشر. نجيب، عز الديم محمد. 2005. أساس التوجمة من الإنجليزية إلى العبية وبالعكس. القاهرة: مكتبة السعي للنشر والتوزع.

Adriana, Iswah dkk. "Kesalahan Kebahasaan Hasil Terjemahan Teks Bahasa Arab ke Dalam Bahasa Indonesia Mahasiswa STAIN Pamekasan 
Nurul Wahdah \& Ade Destri Deviana: Jaudah Tarjamah Mustakhlashat al Buhuts Al Jami'iyyah Min al Lughah al Indunisiyyah Ila al Lughah al 'Arabiyyah Lada Thalabah Qism Ta'lim al Lughah al 'Arabiyyah Fi Jamiah Palangkaraya

Pengguna Google Translate." Nuansa (Juli-Desember 2012) Vol. 9 No. 2

Corder. S. P. Error Analysis and Interlanguage. New York: Oxford University Press. 1981.

Dulay, Heidi, Marina Burt dan Stephen Krashen. Language Two. New York: Oxford University Press. 1982

Ellis, R. 1986. Second Language Acquisition. Oxford: Oxford University Press.

Fisiak, Jacek. Contrastive Linguistics and the Language Teachers. Oxford: Pergamen Press. 1981.

Khoiruman. Analisis Kesalahan dalam Menerjemahkan Bahasa Arab ke Bahasa Indonesia di Madrasah Tsanawiyah Darul Ulum Ngabar Jetis Mojokerto. Undergraduate Thesis: UIN Sunan Ampel Surabaya. 2009

Lubis, Ismail. "Ihwal Penerjemahan Bahasa Arab Ke dalam Bahasa indonesia." Humaniora (2004) . Vol. 16

Munip, Abdul. "Problematika Penerjemahan Bahasa Arab ke Bahasa Indonesia: Suatu Pendekatan Error Analiysis." Al-Arabiyyah (Januari, 2005) Vol 1 No. 2

Munawwir, Achmad Warson. Kamus Al-Munawwir Arab-Indonesia. Cet. Ke-2. Surabaya: Pustaka Progressif. 2002.

- Kamus Al-Munawwir Indonesia-Arab. Cet-2. Surabaya: Pustaka Progressif. 2007.

Richards, Jack C. Error Analysis: A Perspective on Second Language Acquisition. London: Longman Group. 1985.

Tyas, Mohammad Shandy. Kesalahan Dalam Penerjemahan Penggunaan Uslub Nafyi Indonesia-Arab (Analisis Kesalahan pada Mahasiswa Jurusan Pendidikan Bahasa Arab Universitas Negeri Jakarta. Skripsi: Jurusan Bahasa \& Sastra Arab Fakultas Bahasa dan Seni Universitas Negeri. Jakarta. 2016.

Tarigan, Henry Guntur dan Djago Tarigan. Pengajaran Analisis Kesalahan Berbahasa. Bandung: Penerbit Angkasa. 1988. 